\title{
Developing Customer Solutions for Subsistence Marketplaces in Emerging Economies: a Bottom-Up 3C (Customer, Community, and Context) Approach
}

\author{
Srinivas Venugopal $^{1}$ - Madhubalan Viswanathan ${ }^{1}$
}

Published online: 28 April 2015

(C) Springer Science+Business Media New York 2015

\begin{abstract}
This article demonstrates why and how bottom-up understanding and local collaboration can enable outside entities to design context-sensitive solutions in subsistence marketplaces in emerging markets. Using the literature, we argue that external entities need to understand subsistence marketplaces from the bottom-up in terms of customers/consumers, communities, and the larger context. In turn, they should design context-sensitive core solutions that involve a true collaboration with the preexisting entrepreneurial ecosystem. We use a case study where the first author had direct involvement in implementation to abstract generalizable insights and further assess our arguments with two other case studies from a different organizational context. We draw on these insights to derive implications for marketing management in subsistence marketplaces.
\end{abstract}

Keywords Subsistence enterprises · Subsistence enterprises ecosystem $\cdot$ Context sensitivity $\cdot$ Education enterprises

\section{Introduction}

Subsistence marketplaces lie in the shadows of emerging markets, often lost in the focus on large, emerging middle-class and affluent consumers in such countries as India and China [8]. Nevertheless, typically, a majority of consumers in emerging markets live within a range of low-income levels described as subsistence marketplaces [35]. The notion of

Srinivas Venugopal

venugop1@illinois.edu

1 University of Illinois at Urbana Champaign, 1206 South Sixth Street, 350 Wohlers Hall, Champaign, IL 61820, USA subsistence, as used in this stream of research, circumscribes a broad range of low-income households experiencing a constant struggle in meeting life's basic needs. The term, subsistence, essentially emphasizes the qualitative nature of life circumstances in barely making ends meet, complementing quantitative descriptors, such as those based on dollars-aday. As such, the term "subsistence" parallels terms such as poverty as well as the "bottom of the pyramid." Unique to the stream of the subsistence marketplaces literature has been its focus on the intersection of poverty and marketplace exchange using a bottom-up approach. Subsistence marketplaces constitute as much as $60 \%$ of the nation's gross domestic product (GDP) in emerging markets as compared to around $10 \%$ of the GDP in developed nations [41]. Much of marketplace exchange in emerging markets takes place in subsistence marketplaces. This is in sharp contrast to developed nations where consumers largely interact with organizations, within formal institutional contexts. The specific focus of this paper is on how external entities can develop solutions for subsistence marketplaces that are embedded within emerging markets. We motivate our general focus on subsistence marketplaces followed by our specific focus on external entities.

For a number of reasons, subsistence marketplaces provide a unique pathway to learning about emerging markets. First, they represent a high proportion of consumers in emerging markets (over 2.7 billion globally), and an extraordinary opportunity to both try out product offerings and reach a much larger proportion of consumers [15, 27]. Second, they represent the repository of culture, as middle and upper-middle class consumers increasingly bear greater similarity with other such markets around the world [8]. Characterized by low literacy as well, subsistence marketplaces, although having increased exposure in the twenty-first century through the Internet and television, do not share the common knowledge base that typifies more educated segments of society who interact 
across geographic boundaries. To learn about the cultural traditions of emerging markets, there is no better place to start than at the foundation - in subsistence marketplaces where culture is preserved and culture sustains day-to-day life [37]. Third, subsistence employees provide customer service, subsistence entrepreneurs serve as partners, and subsistence producers are at the source of supply chains in emerging markets $[24,37]$. Organizations cannot afford to neglect understanding potential and current employees, partners, and suppliers in subsistence contexts [40]. Fourth, many consumers in subsistence marketplaces or their children are the future lowermiddle and middle class, offering organizations the opportunity to develop customer relationships and brand loyalty as their buying power or those of their children increases. Fifth, innovating for subsistence marketplaces offers the opportunity for innovating from subsistence marketplaces, referred to as reverse innovation [13]. Innovative solutions developed in the extreme constraints of subsistence marketplaces may in turn translate to solutions for higher income segments in emerging markets as well as to segments in advanced economies.

In a related vein to research on emerging markets, the body of knowledge on poverty in business research has been growing exponentially over the past decade [17, 18, 21, 22, 35]. This research has spanned the spectrum from studying subsistence consumers and entrepreneurs to business policy for subsistence markets [18, 22, 37]. On the practice side, a number of large firms have turned their attention towards the bottom of the pyramid (BoP) market, which, they believe, represents a substantial untapped market that can drive business growth [23]. This field of study is of central importance in the global crusade for poverty reduction and warrants increased attention owing to its relevance. Businesses could emerge as major players in meeting customer needs in subsistence marketplaces, thereby creating both economic and social value [21]. In this regard, global entities such as the United Nations view businesses as important partners in meeting the millennium developmental goals [20].

Many solutions are developed for subsistence marketplaces that are judged to be innovative by outside observers but enjoy limited success in local contexts. Consider the example of Playpumps International. Playpumps strives to solve water problems in Africa using children's merry-go-round to pump water to an overhead tank, thereby solving community's drinking water problem. The venture attracted millions in funding with the aim of providing clean drinking water to over 10 million people by 2010 [32], but enjoyed limited traction in the field. Failures were attributed to factors such as lack of maintenance personnel in local contexts [7]. Such failures in subsistence marketplaces often stem from a lack of bottom-up understanding of local realities [40].

Our motivation to study how external entities can design solutions for subsistence marketplaces is related to the state of this specific stream of research. Despite the growing scholarly work on low-income markets, external organizations working in poverty contexts have experienced limited success in terms of being able to successfully offer essential products and services such as health care and education over long time periods [26]. We define external organizations as those that originate in the formal economy and operate within the institutional norms of the formal sector. This is in contrast to organizations that originate within subsistence marketplaces, are selfevolved by the poor, and operate in the informal economy [40].

External organizations operating in contexts of poverty in emerging markets face a number of challenges. The first challenge is faced by managers of external organizations in relating to life conditions of those living in poverty. Inability to relate to consumer's life conditions and needs can create challenges in developing appropriate products and solutions [39]. This is true even for middle-class managers in emerging markets. Secondly, subsistence marketplaces represent a preexisting exchange ecosystem, constituted by microenterprises and consumers, and governed by norms such as empathetic exchange, orality, and relational exchange [40]. These norms, values, and beliefs, which are self-evolved within low-income communities, conflict with the norms, values, and beliefs of external, formal market institutions [42]. Consequently, external organizations operating in low-income communities face the challenge of negotiating these differences at the level of the community and the larger context [6]. Prior literature suggests that external marketing organizations face two types of tensions in subsistence marketplaces. First, they face the task of harmonizing the dual institutional logics of creating social and financial value [3]. Second, spawned within the context of the formal economy, these external enterprises face the need to negotiate the distinct sociocultural and contextual realities across informal subsistence marketplaces they wish to enter. In this article, we focus on the challenges that organizations face and outline ways of overcoming them in delivering high-quality alternatives to those living in poverty. In this regard, we note that hybrid organizations, which combine social and economic goals, are at the forefront of engaging in subsistence marketplaces and provide a rich source of insights [5].

In keeping with a bottom-up approach epitomized by the subsistence marketplaces literature, in this research, we study how micro-level, bottom-up understanding can be used by entities external to such marketplaces to design contextsensitive solutions. We draw from the literature on marketplace exchange within subsistence marketplaces as well as external ventures operating in subsistence marketplaces to derive our model. In addition, we also draw from three case studies of education ventures, operating across rural and urban subsistence marketplaces, to abstract generalizable insights. Distinct from the direct study of subsistence consumers and entrepreneurs that has typified the subsistence marketplaces 
stream, our data is from decision makers in outside entities, which provides a different vantage point for analysis thereby uncovering new insights. Based on our analysis, we argue that external entities need to understand subsistence marketplaces from the bottom-up in terms of customers/consumers, communities, and the larger context. In turn, they should design context-sensitive solutions that reflect such understanding by collaborating with subsistence entrepreneurs. We then derive implications for marketing management. Our contributions are at a number of levels of marketing theory, the broadest being the need to focus on multiple levels of analysis in designing solutions beyond the customer, as assumptions that can be made for customers in advanced economies in terms of shared infrastructure, institutional mechanisms, and knowledge do not hold in subsistence marketplaces. Theoretical insights come from focusing on these extreme contexts for our research. A specific insight stemming from our research is that firms operating in subsistence marketplaces have to emphasize "market development" over "market orientation."

The article is structured as follows. The following section of the article reviews the literature related to subsistence marketplaces. This is followed by the method and findings of a qualitative study of decision makers at organizations engaged in these marketplaces. The subsequent section presents the case study of an educational enterprise in rural subsistence marketplaces in South India, followed by case studies of two other educational social enterprises. The article concludes with a section on implications for research and practice in emerging markets.

\section{Literature Review}

Previous studies on subsistence enterprises have explored the characteristics of subsistence marketplace interactions at the transaction level as well as the marketplace level, with emphases on subsistence consumers and entrepreneurs [40]. The larger context of subsistence has been described in the vast literature on poverty spanning many disciplines. The lack of proper infrastructure and basic necessities that is taken for granted in relatively resource-rich settings leads to uncertainty in all aspects of day-to-day life. At the context level, prior research on poverty has highlighted the debilitating effects of lack of access to finance, markets, and property rights $[10,16,31]$. Past studies have also uncovered the strong interlinkages between poverty, food security, infrastructure, and water $[2,30]$. Uncertainty in most realms of life is a central feature in these contexts.

At the marketplace level, subsistence marketplaces are seen as being resource-poor with regard to income and literacy but potentially resource-rich in terms of social relationships, with interactions characterized by "1-to-1" interactions between buyers and sellers [40]. Exchanges have been described as being fluid with responsive buyers and sellers, and a constant demand for customization. The interactional environment is characterized by enduring relationships and interactional empathy, and the larger context is characterized by pervasive interdependence and orality [40]. Individual-level cognitive constraints relating to low literacy and low income and consequent difficulties with abstract thinking and envisioning the longer term have been noted along with tendencies to engage in concrete thinking and pictographic thinking [36]. Similarly, affective consequences including the need to maintain selfesteem in marketplace interactions and the role of dignity have been studied as well in low-literate low-income consumers in advanced economies and in subsistence marketplaces $[1,37]$. Also emerging from this literature is the nature of decision making, sacrificing functional attributes for the sake of protecting self-esteem and focusing on the relationship rather than the transaction.

A multilevel analysis of products/households, relationships, and the social milieu provides insights for the design of solutions by outside entities, who typically begin with lack of familiarity with these radically different contexts [34]. Severe resource constraints in the face of immediate basic needs and choices between buying, making, or simply foregoing emphasize the need for products to better basic life circumstances. An intensely 1-1 world with strong word-of-mouth emphasizes the need for trust and fairness in relationships [38], and marketplaces characterized by myriad and varied group influences, and fragmented small markets, emphasize the need to negotiate the social milieu. Business models in this regard have discussed the possibility of doing good and doing well [21], with the line of reasoning even being extended to the essential role of product-relevant social good in order to succeed [38]. In terms of product design and development, the literature provides a number of insights about understanding the marketplace-identifying critical and aspirational needs and envisioning usage situations - product design - emphasizing design for customization, low-literate users, multiple purposes, and local sustainability, and development and delivery - and leapfrogging lack of infrastructure or leveraging existing infrastructure, add-on to existing products, and developing product-relevant infrastructure [39].

Past studies have also focused on subsistence entrepreneurs, with research offering insights on how they have intimate knowledge of these marketplaces and possess different types of social capital. They manage relationships with and move resources across three distinct but interdependent subsystems of family, vendor, and consumer [37]. Subsistence entrepreneurs have been argued to have both strengths and vulnerabilities, emphasizing the need for outside entities to provide appropriate support while collaborating with them [24]. They negotiate a variety of forms of social capital in day-to-day activities spanning the domain of suppliers, consumers, and household [37]. Some at the upper end of the 
subsistence entrepreneurship continuum have been labeled as transformative subsistence entrepreneurs, reflecting the dimensions of both their own economic growth and that of the community they are part of [28].

Combining our understanding of subsistence marketplaces, implications for outside entities, and the role of entrepreneurs, we assess how such entities develop understanding of customers/consumers, communities, and context, as well as how they develop context-sensitive solutions through collaborations with entrepreneurs. As illustrated by the entire stream of research on subsistence marketplaces, the intersection of poverty and marketplaces has not been studied in a sustained manner using a bottom-up approach at the microlevel. As such, the insights developed here have important implications for external entities in terms of creating solutions. Past research within this stream has examined implications in this regard such as from the perspective of product development [39] and in interacting with the subsistence entrepreneur or subsistence consumer-merchant ecosystems [37]. From a relatively mesolevel, the BoP literature has provided complementary insights as well. The starting point for the BoP stream of work has been organizations working in these contexts, when compared with the subsistence marketplaces stream, which has focused on individuals and communities and microlevel understanding on such topics as thinking, coping, and marketplace exchanges.

\section{Method}

We conducted three case studies of organizations engaged deeply in subsistence communities in order to meet the key research goal of "context preserving theory building" [4]. Marketing in subsistence contexts is a phenomenon of recent origin, and therefore, case studies enabled us to obtain rich and textured qualitative data [29]. Case studies are conducive to shedding light on organizational action in novel settings, characterized by a dearth of thick descriptive accounts [11]. Given that theoretical development in this arena of research is in its nascent stage, "discovery oriented" inductive research is more appropriate in gleaning original insights to aid in theoretical development. Case studies, therefore, offer the promise of providing naturalistic and holistic data in order to build theory that is rooted in the realities of subsistence contexts [39]. Given the state of knowledge in this area, our method was chosen to gain new insights from cutting edge organizational practices in subsistence marketplaces. Our selection of case studies was informed by our theoretical concerns [11]. We deliberately selected cases to maximize our insights. Our sampling strategy was informed by the theoretical goal of understanding the tensions between harmonizing both social and financial value and negotiating informal subsistence marketplaces as well as their resolution. Within the domain of social enterprises, we focused our attention on an educational enterprise. Prior research on subsistence marketplaces brings to the fore the emphasis placed on children's education by consumers in these markets [35]. The centrality of education as a capacity building service of immense social value in these contexts informed our choice of sectoral focus. An additional reason for our focus on education sector is that it requires expertise in service delivery. Prior research has examined business models wherein self-help-group women have been employed as distribution agents for a company's products such as soaps and shampoos [25]. Our objective in this research has been to examine how external enterprises can harness the expertise and strengths of entrepreneurs within these contexts while addressing some of their vulnerabilities.

As substantiated above, we purposively sampled three social enterprises operating in the education domain. The first author was involved in implementation of the first venture, which served as the primary context for generating insights. Two additional case studies were conducted in different organizational contexts. These case studies ensured that the insights generated are general and not linked to specific aspects of organizations. All of these social enterprises had been operating for more than 2 years and had presence in many states across India. In conducting the case studies, we interviewed six individuals from these social enterprises. We specifically selected informants with field-level experience who were aware of the tensions faced by the organization on a day-today basis in negotiating the local landscape and creating value. In addition to our data from qualitative interviews, we drew from organizational documents such as annual reports, organizational websites, published media articles, and our field notes and reflections. In keeping with our sectoral focus on education, our case data comes from education ventures. Noteworthy here is our focus on social or hybrid organizations (combining social and economic value creation) rather than large corporations, covered in the BoP literature. The phenomenon of hybrid organizations has been on the rise over the last decade, but remains an under researched subject. There is much we can learn from such organizations, which, in turn, have implications for a variety of organizations endeavoring to create solutions for subsistence marketplaces. These hybrid and social enterprises are at the cutting edge in working with communities. Studying hybrid organizations is particularly important because creation of economic and social value is intertwined in subsistence marketplaces [38]. We focused on three organizations described briefly in Table 1.

The qualitative textual data generated through various sources such as interviews, observations, website, and reports were analyzed by all the authors. Data were analyzed independently by the authors. Periodic discussions were held for each case to compare emergent themes. The first goal of the researchers was to understand each case in its entirety before looking for more abstract emergent themes across cases. In accordance with the recommendations of grounded theory, 
Table 1 Description of hybrid organizations

\begin{tabular}{|c|c|}
\hline Name & Description \\
\hline $\begin{array}{c}\text { Venture } \\
1\end{array}$ & $\begin{array}{l}\text { Venture } 1 \text { is a technology based, education service provider, operating in the low-income markets of rural Tamil Nadu, India. It was started as a } \\
\text { project in mid-2007 and scaled to cover } 80 \text { villages across eight districts of Tamil Nadu within } 2 \text { years. Venture } 1 \text { had several distinguishing } \\
\text { features that characterize its design of a solution and a business model: (a) its deep understanding of end user and needs, low-income rural } \\
\text { markets at the level of consumers, communities and context; (b) its partnership with preexisting village-level subsistence enterprises in the } \\
\text { area of education; and (c) its adoption of technologies that were designed specifically to suit the physical, financial, and social conditions } \\
\text { and existing ecosystem of rural India. } \\
\text { - Market: rural villages } \\
\text { - Key purpose: education } \\
\text { - Scale: } 80 \text { villages ( } 1 \text { state in India) } \\
\text { - Years in operation: } 2007-2009\end{array}$ \\
\hline $\begin{array}{c}\text { Venture } \\
2\end{array}$ & $\begin{array}{l}\text { Venture } 2 \text { is an Indian social enterprise committed to sustainable, equitable, and just development. Venture } 2 \text { has community-based programs } \\
\text { spanning areas such as agriculture, energy, education, health, livelihoods, women's empowerment, and social justice. Educational } \\
\text { initiatives are the cornerstones of venture 2's activities. Currently, venture } 2 \text { has a presence in over } 1000 \text { villages in south India. They } \\
\text { operate after-school education centers in these villages, run by local teachers. The organization charges a small fee to cover the expenses of } \\
\text { running the local center and paying the teachers' salaries. Venture } 2 \text { also works in urban low-income communities and, in addition to the } \\
\text { education services, also offer services such as healthcare and livelihoods development based on the needs of the community they operate in. } \\
\text { - Market: rural villages and urban slums } \\
\text { - Key purpose: community development with focus on primary education } \\
\text { - Scale: Over } 1000 \text { villages ( } 22 \text { states in India) } \\
\text { - Years in operation: } 2003 \text {-present }\end{array}$ \\
\hline $\begin{array}{c}\text { Venture } \\
3\end{array}$ & $\begin{array}{l}\text { Venture } 3 \text { is an Indian social enterprise, focused on work force development initiatives. Their programs link training and livelihoods for } \\
\text { disadvantaged young adults from low-income communities. Venture } 3 \text { offers academic, vocational, and occupational programs in poor- } \\
\text { urban, semi-rural, rural, and tribal areas. The organization adopts a community-based approach to designing and delivering various } \\
\text { educational services. This involves working closely with community members, seeking their participation and support in organizational } \\
\text { activities, and evolving community specific solutions. } \\
\text { - Market: rural villages and urban slums } \\
\text { - Key purpose: workforce development } \\
\text { - Scale: } 95 \text { training centers across } 15 \text { states of India } \\
\text { - Years in operation: } 2003 \text {-present }\end{array}$ \\
\hline
\end{tabular}

we used the extant literature on subsistence marketplaces as though it were an additional informant [12]. Differences in interpretations were resolved through a process of negotiation to arrive at a consensus. Our research led to a number of insights that we have organized by understanding customers/consumers, communities, and the larger context and designing solutions involving local collaboration. We summarize our insights in Fig. 1. In discussing our

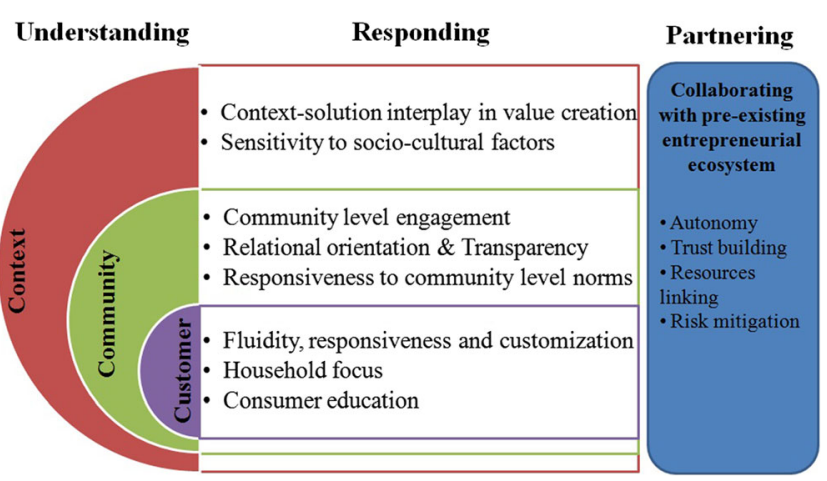

Fig. 1 A holistic approach to understanding and responding to consumer needs in subsistence marketplaces findings, we adopt the following mode of presentation. We start each section with a description of our primary case data. Subsequently, we present the abstract themes that emerge from these data and provide corroborating evidence from the other two case studies.

\section{Findings}

In the following section, we present our key findings organized into themes at the levels of context, community and customer (see Fig. 1). These themes were common across the three ventures in our sample. We note that there were some subtle differences in specific tactics adopted by the ventures depending on the nature of the local contexts they were operating in (for example, densely populated urban slums versus sparsely populated and isolated rural communities). The specific focus of this paper, however, is on understanding the overarching themes that are common across the three ventures. A deeper investigation on tactical variations across the three ventures, and within each venture based on varying contexts of operation, is left for future research. 


\section{Understanding and Responding to Larger Context}

Delivering education services in low-income rural markets of India present a number of challenges. The rural markets are highly fragmented and geographically dispersed. They are characterized by severe shortage of teachers and education infrastructure. To overcome some of these challenges, venture 1 adopted a web-based model of service delivery, accessed by rural students through village-level centers equipped with computers and connectivity.

The underlying communication infrastructure was developed in a leading technological institute in India to suit the physical, social, and economic realities of rural India. The technology was optimized in a way that required low capital investment at the village-level entrepreneur's end and greater investment at the service provider's end. This feature of the technology made it appropriate for low-income rural markets with limited investment and risk-bearing capability. The hardware was designed to withstand the harsh environmental conditions prevalent in rural India. The digital equipment was supplemented with power electronics that enabled continuous operation in the face of power cuts or voltage fluctuations, both of which are pervasive in these contexts. In addition, the hardware was also designed to require minimal maintenance, as it was difficult to find technically trained service providers to maintain the equipment in rural areas.

The process of evolution of the firm's service delivery model highlights the significance of achieving context sensitivity in creating a compelling value proposition for subsistence consumers. The venture began by delivering standardized digital content through village-level computer centers. A few months into the pilot, it became clear that, to obtain enhanced learning outcomes, there was a need to offer culturally relevant content that students could better relate to. This led to development of digital content that was consistent with the cultural context in rural south India (example in Fig. 2). These content objects used images and stories that reflected the local

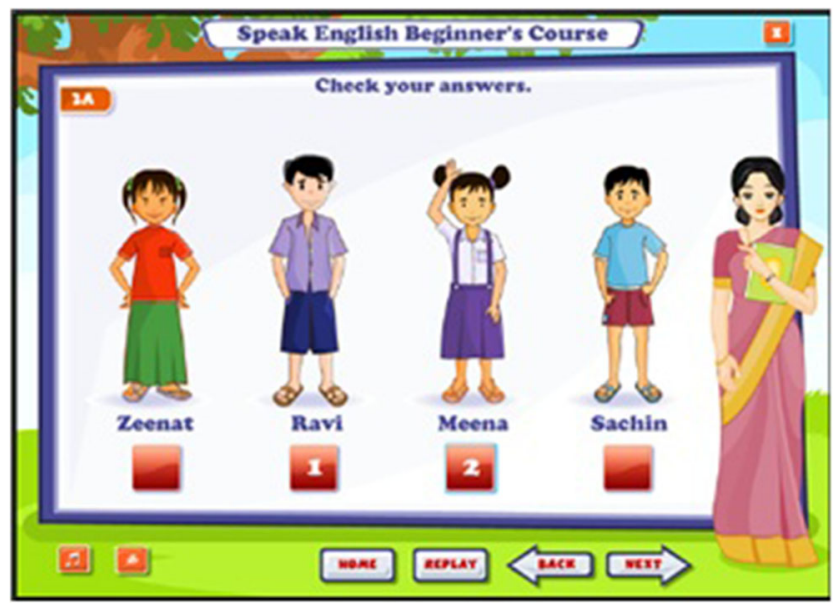

Fig. 2 Culturally relevant course content cultural practices. Further, all the digital content used voiceover in local language owing to the strong tradition of orality in these contexts. Therefore, adapting to the local cultural context was a key strategy on the part of the venture.

\subsection{Context-Solution Interplay in Value Creation}

The adaptation of the venture in entering informal subsistence contexts is illustrative of several challenges faced by the venture. A close examination of the responses of the organization reveals some important insights. One such insight is the need to understand the context-solution interplay in value creation. As Day [9] observes, the value of a product or service resides not in the product or service per se but the value consumers are able to derive from it. Often times in resource-constrained subsistence marketplaces, the supportive ecosystem to derive value from the product does not exist. Therefore, firms operating in subsistence marketplaces have to factor in contextual factors such as availability and poor quality of electric power, availability of trained maintenance personnel, and access to finance for consumers. In delivering its core service of education, venture 1 had to incorporate these peripheral services in order to enable consumers to derive value from its core services. Our case data from venture 3 reinforce this point. Our informants revealed to us instances wherein women students dropped out of their tailoring course not because of the quality of the course itself but because of lack of public toilets that they could use during their time at the training center. Issues such as these, which would be taken for granted in affluent contexts, become central considerations in subsistence marketplaces. Our informants also revealed to us the need to adapt their vocational education services in each context based on the jobs available in the local ecosystem. Offering the same set of courses in all contexts was found to be untenable because, in each context, there was a need for different types of skills based on the local economy. Customers found greater value in vocational courses that were in line with the specificities of the local economy.

\subsection{Sensitivity to Socio-cultural Factors}

In addition to contextual factors discussed above, another important issue that emerges from our data analysis is the need to adapt to the local cultural factors. Our case data indicate how venture 1 generated its course content to fit the local cultural norms and practices, and predominant mode of communication. Venture 2's practice of using road shows and street plays in communicating with subsistence consumers reinforces the need to adopt means of communication and delivery that are consonant with the local cultural norms and practices. In another village in a socially conservative region, venture 1 conducted exclusive batches for female students that had to be run in the afternoons. This was their response to the cultural norm 
that emphasized gender segregation and imposed restrictions on the mobility of women.

\section{Understanding and Responding to Community}

In the previous section, we described factors related to the overarching context elements such as cultural norms and supportive ecosystems for value creation. In this section, we focus on factors related to the social system of community, which has been found to be an important level of analysis in subsistence contexts [40].

A unique feature of venture 1's efforts was engagement and adaptation at the community level. Prior to entering each village, the representatives of the venture forged a relationship with the elected representatives in the village as well as the local school authorities. It was important to form a relationship with these community-level stakeholders to indicate that the objective of the new venture was not to disrupt the prevailing educational system but rather to supplement it. Further, the venture also has to adapt its course offerings and operations to suit community-level factors. For example, in agrarian villages with students from farming households, the fee payment schedules were optimized in a manner that involved bulk payments in the harvesting season since cash flow in these households are cyclical in nature. These activities of the venture reinforce the need to understand and respond to communitylevel factors in order to create value in subsistence contexts.

\subsection{Community-Level Engagement and Responsiveness to Community Norms}

There are several key insights that emerge from the analysis of venture 1's efforts to adapt to community-level factors. Prior research uncovers the strong community-level norms of reciprocity that facilitate exchange in subsistence marketplaces. Consequently, external ventures entering subsistence communities must adapt their efforts to negotiate these communitylevel factors and not cause disruptions in these preexisting exchange systems. The literature underscores that informal subsistence marketplaces differ in terms of beliefs, values, and norms as compared to formal economies [42]. As noted earlier, the social milieu is complex and blurs with the marketplace [38]. Consequently, external social enterprises operating in subsistence markets must engage not just at the individual consumer level but also at the community level. Community engagement involves building long-term relationships and trust to acquire goodwill and legitimacy within the context. Our data from venture 3 is in line with these arguments. Our informants discuss in detail how they had to engage with the whole community before offering their services within the community. They explained to us that communities tend to have shared norms that have a strong bearing on the behaviors of individuals within the community. Unless engagement is established at the community level, organizations offering their services within communities might not find customers. For example, venture 3 had to locate its training centers in a neutral place because two fisherman communities had a conflict, and, consequently, members from one community would not enroll for training if the training centers were located in the other community. Even if the training was perceived as being of value, community-level factors might constrain the individual customer's ability to access the training.

\subsection{Relational Orientation and Transparency}

Community-level engagement required a relational orientation with the community rather than arms-length transactions. For example, venture 3 faced severe backlash from local communities for allowing interactions between boys and girls. This was because such interactions were considered culturally inappropriate within these villages. The venture engaged in intense dialogue with local community members to address these concerns. The very fact that external firms and local communities come from different institutional contexts leads to the emergence of such situations of conflict. A relational orientation is of central importance in addressing these situations of conflict. Another issue that came to surface was social stratification within communities, which the organization dealt with explicitly through constant communication and counseling at the community level. A common thread that runs through all our cases is the relational orientation that these external ventures demonstrated at the community level. By establishing and maintaining a relationship at the community level and through transparent operations, these ventures endeavored to obtain legitimacy in these communities. The importance of enduring marketing relationships in subsistence marketplaces has been emphasized in the literature [40]. Transparency was a central strategy on the part of all these ventures. Explaining who the external entity is to the local community is critical in gaining acceptance. It is not just a byproduct of providing services or doing business but often essential in order to do business. For example, venture 2 held explicit discussions with community leaders and communicated to them (a) who they were (identity), (b) what their intentions were (goals), and (c) what they will and will not do (actions). This again underscores the idea that entering and operating within local subsistence communities is an intensely social process, in addition to being a strategic one. 


\section{Understanding and Responding to Customer/Consumer Needs}

\subsection{Fluidity, Responsiveness, and Customization}

The preceding section enunciated how content was designed to reflect the local cultural context. However, access to culturally relevant content addressed only one dimension of the problem. Venture 1 faced several issues at the level of individual consumers and continuously learned and responded to these needs. Firstly, a model that was merely based on system-student interaction imposed limitations on the learning outcomes that could be achieved. Acting on this insight, the venture created a virtual learning ecosystem that enabled peerpeer and student-teacher interaction around the culturally sensitive digital course material. The virtual platform was open for subject matter experts outside the firm to author and deliver course content. This led to a diversity of course content reflective of the socio-cultural diversity characterizing the target market. Such an ecosystem, aside from providing access to digital course content, provided students virtual access to teachers from geographically dispersed locations, thereby overcoming the issue of teacher availability at the village level. Although the participatory service delivery model proved more effective than a top-down approach, user studies revealed that a significant fraction of students were inhibited from actively interacting with peers and teachers, as the mode of communication was text-based and in English. A large proportion of the students attended government schools where the medium of instruction was Tamil (the local language). Students were accustomed to interacting orally in Tamil. A system relying on text-based interactions in English was not consistent with the local practices. In response to this finding, features were incorporated into the platform that enabled voice-based interaction between participants in local languages. The ability to use a natural mode of communication in the local language fostered greater interactions among teachers and students, consequently leading to superior learning experience for the students. Subsistence marketplaces are characterized by pervasive oral interaction [40]. Systems that enable harnessing of this fundamental characteristic are more suitable for these contexts. The high degree of adoption of mobile phones in low-income markets highlights this issue. Subsistence consumers are faced with extreme resource constraints and uncertainty arising from income and consumption shocks [19]. Consequently, empathy and flexibility play a critical role in marketing exchange [40]. As noted earlier, customization, fluidity in transaction, and responsiveness are important in order to meet the unique situation specific needs of each consumer.

\subsection{Household Focus and Customer Education}

Venture 1 also held frequent meetings with parents of students in order to demonstrate to them what the students were learning at the centers and what opportunities it opened up for students. Engaging with parents was pertinent because decisions of continuing education or sending the child to work for income are made at the household level. There are constant trade-offs being made at the family level to address the immediate survival need or to pursue growth needs thorough longterm investments such as education. Therefore, engagement with parents was a key strategy on the part of the venture.

Gummesson [14] points out that value is not inherent to a good or service but is realized when a consumer derives value by utilizing the product or service. In subsistence contexts, organizations often have to engage in consumer education to facilitate the process of value realization. Ready awareness of needs on the part of consumers cannot be assumed in subsistence contexts. Consumer education goes hand in hand with marketing of social services in these contexts. The immediate family is an important unit of analysis in subsistence marketplaces. Prior research notes that close family often operates as a buffer during times of financial shocks [37]. A number of make-buy-forego decisions are made at the level of the family in order to balance competing needs, and sometimes impossible trade-offs [38]. Therefore, engaging with parents and demonstrating in an accessible manner the problems as well as the solutions becomes pertinent.

Our data from venture 2 reinforces these points. Venture 2 continuously engages with parents, demonstrating to them the state of the child with regard to education and health and explaining the opportunities available to the child. A similar strategy is adopted by venture 3 as well. Venture 2 follows a flexible payment program, which allows students faced with extreme resource constraints to continue participation without paying the fees. This sensitivity of the service delivery model to the unique constraints faced by individual students enable them to continue their services in resource constrained subsistence marketplaces. A rigid delivery model that does not demonstrate such sensitivity is likely to lead to reduced support from consumers over time.

\section{Collaborating with Preexisting Entrepreneurial Ecosystems}

Although the underlying technology assisted venture 1 in overcoming issues such as shortage of teachers, and availability and accessibility of culturally relevant content, the challenge of evolving a business model to viably operate in lowincome rural markets remained to be addressed. As an external entity attempting to reach rural markets, the initial model adopted by the venture was to establish village-level 
distribution points through rural internet kiosks. Rural internet kiosks are village-level centers equipped with computers and connectivity. They are either owned by big companies and run by employees or are owned and run by village-level entrepreneurs. The venture set up a hub and spoke model to support the internet kiosks that were seen as the nodal points for service delivery in the village. This model of operation yielded limited success, which was attributed to the fact that many of the kiosk operators had limited domain knowledge in running education businesses. Further, the employee-run kiosks operating with well-defined process guidelines demonstrated little flexibility in adapting to the conditions of the local market, which are unique to every village.

The solution required was distinct from the traditional BoP approaches of working with self-help groups, setting up micro-franchisees, or working with rural internet kiosks. In addressing the issue of the business model, the venture considered the preexisting network of village-level education service providers who catered to the demand for education services in the local market. These subsistence enterprises evolve in response to the local unmet needs and thrive and flourish in subsistence marketplaces where both the government and organized private sector businesses have had limited success. In the area of education, there are an estimated 54,544 enterprises in the state of Tamil Nadu alone where the venture was operating. These enterprises are generally run by local entrepreneurs equipped with considerable local knowledge, which enables them to continuously adapt to the evolving local needs and economic conditions that characterize their area of operation. This flexibility and adaptability enhance their chances of survival as opposed to top-down businesses with centrally designed products, pricing, and processes. The venture, thus, viewed the subsistence enterprises as emerging from the bottom-up, in response to unmet local needs.

Subsistence enterprises are characterized by fluid one-one buyer-seller interactions [40], and high degree of responsiveness to local market conditions, enabling them to provide customized service to suit the individual consumer needs. However, the small scale of operation limits them from investing in technology, brand building, course content creation, and obtainment of recognized certification, which could lead to greater value for the end customer.

The pervasiveness of subsistence enterprises coupled with characteristics such as local knowledge, domain knowledge, flexibility, and adaptability prompted the venture to partner with them in co-creating value for subsistence consumers. Through a network of locally recruited sales personnel, village-level education enterprises were identified and enlisted. The educational enterprises were offered services such as access to the virtual learning platform, course material, authorized certification, and partnership with recruiters. These offerings were integrated into the solution that these enterprises created for the end customer.
A win-win partnership could, thus, be established, with subsistence enterprises harnessing their strengths in creating a solution for individual consumers, while the venture focused on its core strengths such as in technology development, content creation, branding, and strategic partnerships. This was a suitable model of operation since the venture, as an external entity to the local market, lacked the characteristics required to create individual specific solutions. Simultaneously, the model held value for subsistence enterprises as well as it enabled them to benefit from the ability of the venture to make big ticket investments in such areas as content creation, technology platform development, and branding.

The venture saw itself as part of a larger value network that cumulatively catered to individual- specific needs in subsistence marketplaces. The focus of the venture was on creating critical services for subsistence enterprises that, in turn, leveraged their contextual understanding and unique characteristics to create individual-specific solutions. This approach is in contrast to the traditional approaches where products and services are centrally designed and distribution channels are established to reach low-income markets. This is also in line with the service-dominant logic of marketing that views the firm as being part of a larger value network, co-creating solutions for the end customer [33].

The venture saw subsistence enterprises as their end customers who have complete autonomy over business decisions, such as scale of operation, product mix, and pricing. This meant that each subsistence enterprise evolved in a manner that was harmonious with local conditions. The contrast between two of the education enterprises, one set in a small village in an economically backward region and the other set in a large, economically progressive village, serves to highlight the diversity in evolution based on local conditions. The center set in the smaller village operated on a much lower scale with three computers, while the other center operated with 10 computers. The same courses were priced at a much lower price point in the economically backward village vis-àvis the bigger center making the courses affordable in the local market. Further, the courses with maximum enrolment varied considerably across the two centers determined largely by the alignment of courses with local job opportunities. Basic courses on word processing and desktop publishing tools were preferred in markets with job opportunities in data entry and digital printing, while advanced courses on $\mathrm{C}$ and $\mathrm{C}++$ were preferred in markets with job opportunities in programming.

The preceding examples illustrate the flexibility of subsistence enterprises to respond to social, economic, and personal factors that have a bearing on the economic decisions of the poor. Each enterprise operated within the web of the local business environment, fostering and leveraging relationships with schools, technical service providers, financial service providers, and other local businesses. Such nuanced alignment with local market conditions, at the individual as well 
as the aggregate level, is inconsistent with central design. Although diverse, most of the education enterprise partners of the venture were economically viable. Cumulatively, the subsistence enterprise partners of the venture reflected the inherent diversity of subsistence marketplaces, an issue that has long confounded external businesses. This enabled the venture to scale with diversity through aggregation rather than through replication. The model achieved a win-win by harnessing the responsiveness of the socially embedded subsistence enterprises and the scale advantage of the venture. The ability to customize products and service delivery at the level of local entrepreneur has been identified as an important feature of marketing strategy for subsistence marketplaces [39].

Engaging with local entrepreneurs and harnessing their strength and ameliorating their vulnerabilities emerge as a key strategy in subsistence marketplaces. Without the engagement of local entrepreneurs, a model that only involves external players entering and delivering solutions would face limited success. This is not just because of their inability to tap into the local knowledge of entrepreneurs but also because of their inability to harness the preexisting relationships cultivated by these entrepreneurs over time. Venture 2 adopts a similar model in its operations across 1000 villages. They engage with local teachers in these villages, tapping into not only their domain knowledge but also their relational network and knowledge of the village and individual consumers.

\subsection{Summary Implication for Local Collaborations}

In summary, four key themes emerged across all the three ventures with regard to working with local entrepreneurs. The first is the theme of granting the local entrepreneurs decisionmaking autonomy as they possess unique contextual information to make informed business decisions at the local level. External organizations trying to impose a single template across multiple contexts will constrain the ability of the local entrepreneur in creating customized solutions locally. This was evident in venture 1's model of allowing its local entrepreneurs to adapt to local socio-economic conditions. The second theme is that of trust building with local entrepreneurial partners. Local entrepreneurs are embedded within the social milieu where the social and economic aspects of life are intertwined [37]. Consequently, imposing a transactional exchange model would be a mismatch with the current mode of operation. Building trust and nurturing long-term relationships with local entrepreneurs is an important aspect in working with local partners. Thirdly, although the local entrepreneurs possess nuanced contextual information and rich social networks, they are from resource constrained contexts. These resources could be in the form of capital, infrastructure (physical or technological) or linkages to opportunities outside the local context. Firms could support their local partners by providing access to such resources. Venture 1 enabled this by providing local entrepreneurs access to high-quality teachers from outside the context as well as access to corporate recruiters. Finally, because local entrepreneurs possess limited financial capabilities, they are also limited in their ability in absorbing business risk. Often, growth is sacrificed owing to an inability to absorb more risk. External firms could support local enterprises by absorbing a greater share of business risk. For example, venture 1 designed its technology in such a manner that the initial investment required by the local partner was minimal. If this has not been the case, many local entrepreneurs would have found themselves unable to absorb business risk involved.

\section{Summary}

Our model comprising of the three Cs of customer, community, and context in subsistence marketplaces highlights the importance of understanding beyond the customer to more aggregate levels of analysis, while adopting a bottom-up perspective. Middle- and upper-class customers live in settings that share a number of commonalities that can be taken for granted. However, in subsistence marketplaces, the individual blurs into the community in this world of 1-1 interactions. Negotiating the social milieu, which is blurred with the marketplace, is an important consideration in these settings [38]. Myriad differences at the community level exist across subsistence settings. Commonalities created by education, access to information technology, material comforts, and so forth that characterize middleand upper-class settings are largely absent in subsistence settings. Consumption occurs in close-knit communities and social norms and cultural elements influence one's functioning as a customer. In fact, one's role in the community is deeply intertwined with day-to-day existence, rather than being a factor to consider as is the case in advanced economies.

Additionally, the larger context in subsistence marketplaces can vary from place to place to a much greater degree. Whether the issue is electrification, political stability, or communal harmony, the larger context in which the customer functions need to be understood. For instance, material resources lead to a minimum level of infrastructure being taken for granted as well as some level of cushioning from natural disasters. The availability of energy and water provides a stable context for consumption. Uncertainty, as it relates to necessities, characterizes life in subsistence. Understanding larger contextual elements is critical in this regard.

\section{Implications for Research and Practice}

Our primary research and the case study presented above draws attention to a number of germane issues that warrant deeper research. Most importantly, our research demonstrates what it means to be truly bottom-up in orientation as an 
external entity. Approaches adopted by external entities are sometimes described as bottom-up merely because they involved local individuals or groups in the value chain, such as self-help groups and small resellers. However, the bottom-up orientation begins with a quest for obtaining a nuanced understanding of subsistence marketplaces at the level of consumers, communities, and contexts and subsequently using this understanding to develop context-sensitive solutions. The bottom-up approach is also characterized by a relational orientation seeking to harness and develop the preexisting entrepreneurial talent in these marketplaces rather than viewing them as untapped markets to sell to. The 1-to-1 interactional approach to value creation enables subsistence enterprises to respond to the locally specific economic, social, and personal factors that influence the economic decision making of the subsistence consumer. This approach to value creation goes beyond the notion of transactional exchange of products with embedded value. The 1-to-1 interactional focus enables subsistence enterprises to create solutions for individual consumer as opposed to offering products, thereby creating and capturing value for both consumers and themselves in the constrained context of poverty.

Subsistence entrepreneurs do not act merely as channels for products/service distribution but rather as resource integrators at the local level. They continuously nurture and harness resources such as local knowledge, social capital with value network partners, domain knowledge, and flexibility in order to create a unique solution for individual consumers. Greater understanding is required on the nature of resources they leverage and how they nurture and harness them along the lines of recent work.

Subsistence enterprises collectively create and operate within a larger subsistence enterprise ecosystem. This ecosystem represents a complex network of locally co-evolving enterprises, operating harmoniously in constrained contexts and providing access to a number of support services to each other. The support services are crucial to the survival of enterprises and in catering to end-customer needs. There is limited understanding of how these ecosystems evolve and how entities within the ecosystem interact with mutual benefit. Although these ecosystems have been studied from a macroperspective through measures such as productivity and growth, understanding of how these ecosystems evolve and function as value networks is still in a nascent stage.

This research has two central implications for external firms engaging in subsistence marketplaces. Firms have been argued to need to develop local capabilities in order to operate viably in subsistence marketplaces $[18,26]$ and even ingrain social good into business processes [38]. In this paper, we demonstrate how deeply this notion has to be understood and how, to be truly bottom-up, this approach involves more than just working with some local entities in a superficial capacity. Rather, local entities are central actors in all aspects of the business model. This research presents a model for mutually beneficial engagement between large external firms and subsistence enterprises that combine the benefits of scale of large firms and local capabilities of subsistence enterprises. Harnessing these benefits necessitates viewing subsistence enterprises as part of the value network collectively creating solutions for end-customers as opposed to a viewing them as local distribution points. The model that we advance (pictorially depicted in Fig. 1) reinforces the need for external entities to obtain a bottom-up understanding of subsistence consumers, communities and contexts in order to develop context sensitive and sustainable solutions for these markets. We draw from the literature on marketplace exchange within subsistence marketplaces as well as external ventures operating in subsistence marketplaces in deriving this model. Further, we also use three case studies to support and illustrate aspects of the model. Adopting such a grounded approach to subsistence marketplaces, as argued here, will enable external organizations to create both social and economic value in subsistence marketplaces.

By delving into the intersection of poverty and marketplaces, this work has implications for research and practice in the area of poverty. Our implications are at the level of how organizations can approach, engage in, and design solutions in poverty contexts, based on micro- and mesolevel insights. We unpack a number of key elements from an organizational perspective that have bearing for a variety of sectors of society. For instance, our model can be adapted to services provided by governmental entities. By sharply focusing on the economic and marketplace arena, we develop new insights on an important realm of life in poverty. We do so at a level that has typically been neglected in top-down approaches.

\section{Conclusion}

Subsistence marketplaces lie at the shadow of emerging markets in terms of their visibility when compared to the rising middle class in many countries. Nevertheless, they form a large proportion of emerging markets and represent the roots for many in the current middle class. Understanding subsistence marketplaces in emerging markets provides a window into culture, an opportunity to design for the most challenging of settings, a resource pool of employees, suppliers, and local partners, and relationships with the future middle or lowermiddle class. Such understanding needs to move beyond an exclusive focus on the customer to the large community and context. These elements are intertwined with one's role as a customer, and there are myriad differences in these elements across subsistence settings. Thus, marketing in subsistence marketplaces in emerging markets requires a holistic approach to understanding the three Cs of the customer, the community, and the larger context. 
Summary Statement of Contribution This research contributes to the literature on marketing in subsistence marketplaces, which constitutes a large proportion of emerging markets. We derive and advance a model for external ventures seeking to provide essential products and services in contexts of poverty. We highlight the challenges faced by such ventures and offer practical recommendations for understanding and responding to these challenges. Our model advances marketing theory and informs marketing practice in subsistence contexts.

\section{References}

1. Adkins NR, Ozanne JL (2005) The low literate consumer. J Consum Res 32(1):93-105

2. Alderman H, Garcia M (1993) Poverty, household food security, and nutrition in rural Pakistan. International Food Policy Research Institute, Washington, DC

3. Battilana J, Dorado S (2010) Building sustainable hybrid organizations: the case of commercial microfinance organizations. Acad Manage J 53(6):1419-1440

4. Bonoma TV (1985) Case research in marketing: opportunities, problems, and a process. J Mark Res (JMR) 22(2):199-208

5. Bornstein D (2007) How to change the world: social entrepreneurs and the power of new ideas. Oxford University Press, Oxford

6. Burgess SM, Steenkamp JBE (2006) Marketing renaissance: how research in emerging markets advances marketing science and practice. Int J Res Mark 23(4):337-356

7. Costello A (2010) Troubled water. www.pbs.org/frontlineworld/ stories/southernafrica904/video_index.html (accessed on 24th Feb 2015)

8. Dawar N, Chattopadhyay A (2002) Rethinking marketing programs for emerging markets. Long Range Plann 35(5):457-474

9. Day GS (1994) The capabilities of market-driven organizations. J Mark 58:37-52

10. De Soto H (2000) The mystery of capital: Why capitalism triumphs in the West and fails everywhere else. New York: Basic Books

11. Eisenhardt KM (1989) Building theories from case study research. Acad Manage Rev 14(4):532-550

12. Goulding C (1998) Grounded theory: the missing methodology on the interpretivist agenda. Qual Mark Res Int J 1(1):50-57

13. Govindarajan V (2012) A reverse-innovation playbook. Harv Bus Rev 90(4):120-124

14. Gummesson E (1994) Making relationship marketing operational. I J Serv Ind Manag 5(5):5-20

15. Hahn R (2009) The ethical rational of business for the poor-integrating the concepts bottom of the pyramid, sustainable development, and corporate citizenship. J Bus Ethics 84(3):313-324

16. Kochar A (1995) Explaining household vulnerability to idiosyncratic income shocks. Am Econ Rev 85:159-164

17. Kotler P, Roberto N, Leisner T (2006) Alleviating poverty: a macro/ micro marketing perspective. J Macromark 26(2):233-239

18. London T, Hart SL (2004) Reinventing strategies for emerging markets: beyond the transnational model. J Int Bus Stud 35(5): 350-370

19. Morduch J (1995) Income smoothing and consumption smoothing. J Econ Perspect 9(3):103-114

20. Nelson J, Prescott D (2003) Business and the millennium development goals: a framework for action. International Business Leaders Forum, London

21. Prahalad CK (2005) The fortune at the bottom of the pyramid: eradicating poverty through profits. Wharton School Publishing, Philadelphia

22. Prahalad CK, Hammond A (2002) Serving the world's poor, profitably. Harv Bus Rev 80(9):48-59
23. Prahalad CK, Hart SL (2002) The fortune at the bottom of the pyramid. Strateg Bus 54-54

24. Ramachandran J, Pant A, Pani SK (2012) Building the BoP producer ecosystem: the evolving engagement of Fabindia with Indian handloom artisans. J Prod Innov Manag 29(1):33-51

25. Rangan VK, Sehgal D, Rajan R (2007) "The complete business of serving the poor: insights from Unilever's Project Shakti in India". In: Rangan VK, Quelch JA, Herrero G, Barton B (Eds), Business Solutions for the Global Poor: Creating Social and Economic Value. Jossey-Bass, San Francisco, CA, pp 144-154

26. Ritchie R, Sridharan S (2007) Marketing in subsistence markets: innovation through decentralization and externalization. Adv Int Manag 20:195-214

27. Sheth JN (2011) Impact of emerging markets on marketing: rethinking existing perspectives and practices. J Mark 75(4):166-182

28. Sridharan S, Maltz E, Viswanathan M, Gupta S (2014) Transformative subsistence entrepreneurship a study in India. J Macromark 34(4):486-504

29. Stake RE (1995)The art of case study research. Sage, Thousand Oaks

30. Sullivan CA, Meigh JR, Giacomello AM (2003) The water poverty index: development and application at the community scale. Natural Resources Forum 27(3):189-199

31. Townsend RM (1995) Consumption insurance: an evaluation of risk-bearing systems in low-income economies. J Econ Perspect 9(3):83-102

32. Vandendriessche M (2012) The study of playpumps: merry-gorounds, water, and failures in development AID. http:// unitedexplanations.org/english/2012/03/22/the-story-ofplaypumps-merry-go-rounds-water-and-failures-in-developmentaid/ (accessed on 24th Feb 2015)

33. Vargo SL, Lusch RF (2008) Service-dominant logic: continuing the evolution. J Acad Mark Sci 36(1):1-10

34. Viswanathan M (2010) A micro-level approach to understanding BoP markets. In: London T, Hart S (eds) Next generation business strategies for the base of the pyramid: new approaches for building mutual value. FT Press, Upper Saddle River

35. Viswanathan M, Rosa JA (2007) Product and market development for subsistence marketplaces: consumption and entrepreneurship beyond literacy and resource barriers. Adv Int Manag 20:1-17

36. Viswanathan M, Rosa JA, Harris JE (2005) Decision making and coping of functionally illiterate consumers and some implications for marketing management. J Mark 69(1):15-31

37. Viswanathan M, Rosa JA, Ruth JA (2010) Exchanges in marketing systems: the case of subsistence consumer-merchants in Chennai, India. J Mark 74(3):1-17

38. Viswanathan M, Seth A, Gau R, Chaturvedi A (2009) Ingraining product-relevant social good into business processes in subsistence marketplaces: the sustainable market orientation. J Macromark 29(4):406-425

39. Viswanathan M, Sridharan S (2012) Product development for the BoP: insights on concept and prototype development from university-based student projects in India. J Prod Innov Manag 29(1):5269

40. Viswanathan M, Sridharan S, Ritchie R, Venugopal S, Jung K (2012) Marketing interactions in subsistence marketplaces: a bottom-up approach to designing public policy. J Public Policy Mark 31(2):159-177

41. Webb JW, Bruton GD, Tihanyi L, Ireland RD (2013) Research on entrepreneurship in the informal economy: framing a research agenda. J Bus Ventur 28(5):598-614

42. Webb JW, Tihanyi L, Ireland RD, Sirmon DG (2009) You say illegal, I say legitimate: entrepreneurship in the informal economy. Acad Manage Rev 34(3):492-510 